\title{
Egg consumption and cardiovascular disease among diabetic individuals: a systematic review of the literature
}

This article was published in the following Dove Press journal:

Diabetes, Metabolic Syndrome and Obesity: Targets and Therapy

24 March 2014

Number of times this article has been viewed

\section{Nga L Tran \\ Leila M Barraj \\ Jacqueline M Heilman \\ Carolyn G Scrafford}

Exponent Center for Chemical Regulation and Food Safety, Washington, DC, USA
Correspondence: Nga L Tran

Exponent, II 50 Connecticut NW,

Suite II00, Washington, DC 20036, USA

$\mathrm{Tel}+\mathrm{I} 2027724915$

Fax + I 2027724979

Email ntran@exponent.com
Background: This study reviewed epidemiological and experimental evidence on the relationship between egg consumption and cardiovascular disease (CVD) risks among type II diabetes mellitus (T2DM) individuals, and T2DM risk in nondiabetic subjects.

Results: Four of the six studies that examined CVD and mortality and egg consumption among diabetics found a statistically significant association. Of the eight studies evaluating incident T2DM and egg consumption, four prospective studies found a statistically significant association. Lack of adjustment for dietary confounders was a common study limitation. A small number of experimental studies examined the relationship between egg intake and CVD risk biomarkers among diabetics or individuals with T2DM risk factors. Studies among healthy subjects found suggestive evidence that dietary interventions that include eggs may reduce the risk of T2DM and metabolic syndrome.

Conclusion: Differences in study design, T2DM status, exposure measurement, subject age, control for confounders and follow-up time present significant challenges for conducting a meta-analysis. Conflicting results, coupled with small sample sizes, prevent broad interpretation. Given the study limitations, these findings need to be further investigated.

Keywords: type II diabetes mellitus, diet, cardiovascular risk factors, coronary heart disease, stroke

\section{Background}

Coronary heart disease (CHD) and stroke are leading causes of death in the USA and globally. Elevated serum low-density lipoprotein (LDL) has been identified as a major risk factor for CHD. ${ }^{1}$ Epidemiological studies have shown a relationship between dietary cholesterol and CHD risk, and early metabolic studies have shown a positive relationship between dietary cholesterol and plasma total and LDL cholesterol (LDL-C). ${ }^{2-5}$ These findings, in part, have led to guidelines from the American Heart Association recommending that healthy adults limit cholesterol intake to less than $300 \mathrm{mg}$ per day. Since a large egg contains about $185 \mathrm{mg}$ cholesterol, the American Heart Association recommends restricting egg consumption unless cholesterol intakes from other sources are limited..$^{6,7}$ However, there is a growing body of scientific literature showing a lack of relationship between egg intake and cardiovascular disease (CVD) risk, ${ }^{8-17}$ including two recent meta-analyses that showed no association or dose-response relationship between egg consumption and CHD or stroke. ${ }^{18,19}$ Further, recent dietary guidelines indicate healthy people can consume one egg a day as part of a healthy diet. ${ }^{20}$

The positive relationship between egg intake and CVD risk among persons with type II diabetes mellitus (T2DM) has been shown in several prospective studies. ${ }^{14,21,22}$ 
Further, the direct relationship between egg intake and risk of diabetes has also been shown; however, in several of these prospective studies, dietary factors, in particular saturated fat intake, were not accounted for. ${ }^{14,22}$ T2DM is a metabolic disorder characterized by high blood glucose and develops in the presence of deficient insulin action, which can be attributed to either insufficient production or excretion of insulin, resistance to the actions of insulin, or both. ${ }^{23}$ Clinical definitions for prediabetic and diabetic conditions have been established by the World Health Organization (WHO ${ }^{24}$ and the American Diabetes Association, ${ }^{23}$ based on fasting plasma glucose (FPG) levels 2 hours following intake of oral glucose load (oral glucose tolerance).

Insulin resistance, hypertension, impaired glucose tolerance, elevated FPG, dyslipidemia, abdominal adiposity, obesity, inactivity, and genetic characteristics are among the complex web of risk factors that can indicate risk for future development of T2DM..$^{23,25-29}$ Many of the risk factors for T2DM are also CVD risk factors. Metabolic syndrome (MetS) can be used as a clinical tool to characterize individuals with some combination of CVD risk factors, including diabetes, obesity, dyslipidemia and hypertension. Persons with MetS are at a twofold risk for developing CVD and fivefold risk for T2DM. ${ }^{30-32}$ Diabetes is also frequently called an "independent risk factor" for CVD, ie, independently of LDL-C levels, diabetes increases the risk of CVD. ${ }^{33}$ Hemoglobin A1C (HbA1C), a well-established indicator of overall serum glucose control in diabetic patients, is the most potent predictor of CHD risk. ${ }^{34}$ Inflammation induced by diabetes and insulin resistance can accelerate atherosclerosis in patients with diabetes. ${ }^{35}$ Normal insulin signaling is essential for normal cardiovascular function, and lack of it will result in cardiovascular dysfunction and CVD. ${ }^{36}$ Kidney disease, a well-known complication of diabetes progression, is significantly associated with cardiovascular events, even after correction for classical risk factors, such as diabetes itself, hypertension, and dyslipidemia. ${ }^{37}$ The complex shared risk factors between CVD and T2DM, in combination with diabetes being an independent risk factor for CHD and stroke, pose real challenges in epidemiologic studies that attempt to examine the role of egg intake in CVD risk among diabetics.

The published epidemiological evidence on 1) the relationship between egg consumption and CVD risks among individuals with T2DM and 2) the direct relationship between egg consumption and risk of developing T2DM were systematically reviewed in this study. Published clinical trials and feeding studies that examined the relationship between egg intake and biomarkers of the shared risk factors for T2DM and CHD were also evaluated as a subanalysis in this review.

\section{Current status of knowledge} Literature search

Two initial PubMed searches were conducted to identify epidemiological studies on egg consumption and CVD risk among diabetics (completed June 15, 2011). The first search was conducted using the search terms: "egg or eggs" and "diabetes or diabetic or insulin or resistant or tolerance" and "cardiovascular or stroke or myocardial or coronary or heart or atherosclerosis or CHD or CVD or CAD [coronary artery disease]" without any limitations. Six epidemiology studies on egg consumption and CVD risk among diabetics were found. ${ }^{14,16,21,22,38,39}$ A second search, with broader search terms, including "egg or eggs" and "diabetes or diabetic", and with limitations to human studies and English publications, was conducted and was followed by a hand search. Six studies on egg consumption as a risk factor for diabetes were found. ${ }^{40-45}$ In the hand search, one study on dietary cholesterol and CVD risk among diabetics was found. ${ }^{46}$

Three supplemental PubMed searches were conducted to identify studies that examined the relationship between egg consumption or dietary cholesterol and biomarkers of CHD and T2DM risk, followed with a hand search (completed June 15, 2011). These searches were limited to: humans, clinical trial, meta-analysis, randomized controlled trial, comparative study, English, MEDLINE, and all adult $\geq 19$ years. "Egg or eggs or dietary cholesterol" and "intake or consumption or diet" and "diabetes or diabetic" and "triglycerides or HDL (high-density lipoprotein) or LDL or serum cholesterol or serum lipids" were terms included in the first search, which resulted in four relevant studies. ${ }^{47-50 ~ " E g g ~ o r ~ e g g s ~ o r ~ d i e t a r y ~ c h o l e s t e r o l " ~ a n d ~ " i n t a k e ~}$ or consumption or diet" and "diabetes or diabetic" and "cardiovascular or stroke or myocardial or coronary or atherosclerosis" were terms used in the second search; only one new study was found (Lindeberg et al). ${ }^{51}$ The search terms used in the third search were "egg or eggs" and "metabolic or syndrome or insulin or glucose or impaired or resistant" and "triglycerides or HDL or LDL or cholesterol or lipids or HDL-cholesterol (HDL-C) or LDL-C" and resulted in six studies. ${ }^{52-57}$ In a hand search, one study on the effect of egg consumption and CHD risk among T2DM subjects ${ }^{58}$ and four studies on the effect of egg and egg-containing diet and $\mathrm{CHD} / \mathrm{T} 2 \mathrm{DM}$ risk factors in healthy individuals were found. ${ }^{59-62}$ 
Two later searches were also performed on March 30, 2012 and November 14, 2013. These searches found a new casecontrol study on egg intake and T2DM risk; ${ }^{63}$ a cross-sectional survey that examined modifiable risk factors, including egg consumption, for diabetes; ${ }^{64}$ two prospective cohort studies that followed protein intake from eggs and risk of $22 \mathrm{DM},{ }^{65}$ and egg consumption and risk of T2DM; ${ }^{66}$ and four studies reporting results from the same diet intervention study, in individuals with MetS. ${ }^{67-70}$ Three meta-analyses were published in 2013 that evaluated the association between egg consumption and CVD, with subgroup analyses among diabetics. ${ }^{18,19,71}$ Two of these meta-analyses also evaluated the association between egg consumption and the risk of diabetes. ${ }^{19,71}$

\section{Summary of the published literature Egg consumption and CVD risk in diabetics}

Six prospective cohort studies examined the relationship between egg consumption and CVD risk among diabetics, of which four studies found statistically significant increases in CVD risk and egg consumption, ${ }^{14,21,38,40}$ one study found "suggestive evidence" but no statistically significant increase, ${ }^{22}$ while another study did not find a statistically significant increase but referred to the small number of diabetics in the study. ${ }^{16}$ These studies are summarized in Table 1 and described below.

Hu et al conducted an analysis using data from a prospective study of 37,851 male health professionals and 80,082

Table I Prospective cohort studies on egg consumption and CVD risk among diabetics

\begin{tabular}{|c|c|c|c|c|}
\hline Reference & Population & Exposure & Outcome & Study findings \\
\hline $\mathrm{Hu}$ et $\mathrm{al}^{2 \mathrm{I}}$ & $\begin{array}{l}\text { Health Professionals Follow-up } \\
\text { Study, Nurses' Health Study. } \\
\text { n=37,85I men, } 80,082 \text { women; } \\
\text { diabetic subpopulation } \\
\text { (n not reported) }\end{array}$ & $\begin{array}{l}\text { Usual egg intake; } \\
\text { five groups: }<1,1,2-4 \text {, } \\
5-6 \text { and } \geq 7 \text { eggs } \\
\text { per week }\end{array}$ & $\begin{array}{l}\text { Incident CVD } \\
\text { (nonfatal MI or } \\
\text { fatal CHD) } \\
\text { and stroke }\end{array}$ & $\begin{array}{l}\text { Egg intake associated with increased CHD risk } \\
\text { in diabetics. RR (CHD) for diabetics consuming } \\
\geq \mathrm{I} \text { egg a day compared with those consuming } \\
<\mathrm{I} \text { egg a week: } 2.02(95 \% \mathrm{Cl} \mathrm{I} .05-3.87 ; \\
P \text {-trend }=0.04) \text { for men and } \mathrm{I} .49(95 \% \mathrm{Cl} \\
0.88-2.52 ; P \text {-trend=0.008) for women }\end{array}$ \\
\hline $\begin{array}{l}\text { Tanasescu } \\
\text { et } \text { al }^{46}\end{array}$ & $\begin{array}{l}\text { Age at enrollment } 30-55 \text { years; } \\
n=5,672 \text { women with T2DM }\end{array}$ & $\begin{array}{l}\text { Dietary cholesterol, } \\
\text { total fat, saturated fat } \\
\text { (PUFA, MUFA, etc) } \\
\text { at baseline and follow up } \\
\text { every } 2 \text { years }\end{array}$ & $\begin{array}{l}\text { CVD: nonfatal } \\
\text { MI, fatal CHD, } \\
\text { and stroke }\end{array}$ & 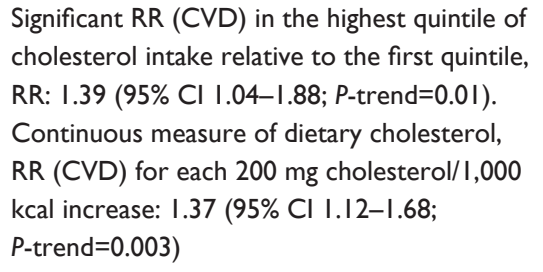 \\
\hline $\begin{array}{l}\text { Trichopoulou } \\
\text { et } \mathrm{al}^{38}\end{array}$ & $\begin{array}{l}\text { Adult Greek volunteers; } \\
\mathrm{n}=815 \text { (oral diabetes medication); } \\
\mathrm{n}=198 \text { (insulin only or insulin } \\
\text { with oral diabetes medication) }\end{array}$ & Usual egg intake (g/day) & $\begin{array}{l}\text { Total death } \\
\text { and CVD death }\end{array}$ & $\begin{array}{l}\text { Intake of } 10 \mathrm{~g} \text { of egg per day (one standard } \\
\text { deviation) associated with a HR of I.54 } \\
(95 \% \mathrm{Cl} \mathrm{I.20-1.97)}\end{array}$ \\
\hline $\begin{array}{l}\text { Qureshi } \\
\text { et } \text { al }^{14}\end{array}$ & $\begin{array}{l}\text { NHEFS: adults } 25-74 \text { years at } \\
\text { baseline; diabetic subpopulation, } \\
n=349\end{array}$ & $\begin{array}{l}\text { Usual egg intake; } \\
\text { three groups: }<1, \mathrm{I}-6 \text {, } \\
\text { and } \geq 7 \text { times per week }\end{array}$ & $\begin{array}{l}\text { Hospitalization } \\
\text { or death from } \\
\text { stroke and CAD }\end{array}$ & $\begin{array}{l}\text { Among diabetics }>6 \text { eggs/week associated } \\
\text { with increased risk of CAD (RR: } 2.0[95 \% \mathrm{Cl} \\
\text { I.0-3.8]). No increased risk for stroke or } \\
\text { ischemic stroke }\end{array}$ \\
\hline $\begin{array}{l}\text { Djousse } \\
\text { and Gaziano }\end{array}$ & $\begin{array}{l}\text { Physicians' Health Study I: } \\
\text { US male physicians, aged } \\
40-85 \text { years at enrollment; } \\
\mathrm{n}=21,327 \text {; diabetic } \\
\text { subpopulation not specified }\end{array}$ & $\begin{array}{l}\text { Usual egg intake; } \\
\text { five groups: }<\mathrm{I}, \mathrm{I}, 2-4 \text {, } \\
5-6 \text {, and } \geq 7 \text { times (egg) } \\
\text { per week }\end{array}$ & $\begin{array}{l}\text { Incident MI } \\
\text { or stroke } \\
\text { and all-cause } \\
\text { mortality }\end{array}$ & $\begin{array}{l}\text { No association between eggs and } \mathrm{MI} \text { or stroke } \\
\text { in diabetics or nondiabetics. } \mathrm{HR} \text { among } \\
\text { diabetics } \geq 7 \text { eggs per week compared } \\
\text { to }<\text { I egg per week: } \mathrm{MI}: \text { I.06 }(95 \% \mathrm{Cl} \\
0.43-2.63) \text {; stroke: } \mathrm{I} .83(95 \% \mathrm{Cl} 0.7 \mathrm{I}-4.23)\end{array}$ \\
\hline $\begin{array}{l}\text { Houston } \\
\text { et } \mathrm{al}^{39}\end{array}$ & $\begin{array}{l}\text { Adults, } 70-79 \text { years; } \\
\text { random sample from Health } \\
\text { ABC Study; black and white, } \\
\text { men and women, } n=I, 94 I ; \\
\text { diabetic subpopulation, } n=34 I\end{array}$ & $\begin{array}{l}\text { Usual egg intake; } \\
\text { three groups: }<1, \mathrm{I}-2 \text {, } \\
\text { and } \geq 3 \text { times per week }\end{array}$ & $\begin{array}{l}\text { Incident } \mathrm{MI} \\
\text { or stroke } \\
\text { and coronary } \\
\text { death occurring } \\
\text { after year } 2\end{array}$ & $\begin{array}{l}\text { Dietary cholesterol and egg consumption were } \\
\text { associated with increased CVD risk among } \\
\text { older, community-dwelling adults with T2DM, } \\
\text { but not among nondiabetics. HR: } 3.66 \text { ( } 95 \% \\
\mathrm{CI} \text { I.09-12.29) and } 5.02 \text { ( } 95 \% \mathrm{CI} \text { I.63-I5.52), } \\
\text { respectively, for the upper versus lower tertile }\end{array}$ \\
\hline $\begin{array}{l}\text { Scrafford } \\
\text { et al }{ }^{16}\end{array}$ & $\begin{array}{l}\text { NHANES III and follow-up survey: } \\
\text { men and women } \geq 17 \text { years, } \\
\text { free of CVD; } n=6,833 \text { men } \\
\text { and } n=8, I I 3 \text { women; diabetic } \\
\text { subpopulation not reported }\end{array}$ & $\begin{array}{l}\text { Usual egg intake; } \\
\text { three groups: }<1,1-6 \text {, } \\
\text { and } \geq 7 \text { times per week }\end{array}$ & $\begin{array}{l}\text { CHD and } \\
\text { stroke } \\
\text { mortality }\end{array}$ & $\begin{array}{l}\text { No increase in CHD or stroke mortalities } \\
\text { in diabetics consuming } \geq 7 \text { eggs/week. } \\
\text { HR (CHD): } 0.97(95 \% \mathrm{Cl} 0.40-2.39) ; \mathrm{HR} \\
\text { (stroke): } 0.32 \text { ( } 95 \% \mathrm{Cl} 0.07-\mathrm{I} .42) \text {; small sample } \\
\text { size, lacked statistical power }\end{array}$ \\
\hline
\end{tabular}

Abbreviations: $A B C$, aging and body composition; $C A D$, coronary artery disease; $C H D$, coronary heart disease; CVD, cardiovascular disease; $C l$, confidence interval; $H R$, hazard ratio; MI, myocardial infarction; MUFA, monounsaturated fatty acid; n, sample size; NHANES, National Health and Nutrition Examination Survey; NHEFS, NHANES I Epidemiologic Follow-up Study; PUFA, polyunsaturated fatty acid; RR, relative risk; T2DM, type 2 diabetes mellitus. 
female nurses, aged 40-75 years (males) and 30-55 years (females) at enrollment, with average follow-up periods of 8 years (males) and 14 years (females). ${ }^{21}$ Egg consumption was measured using a food frequency questionnaire (FFQ) at baseline and every 24 months, and consumption status was classified in five groups: $<1,1,2-4,5-6$ and $\geq 7$ eggs per week. Incident CHD (including nonfatal myocardial infarction [MI] or fatal CHD) and stroke (as reported by participants and confirmed by review of medical records) were examined. Their secondary analysis of 5,309 subjects with diabetes (sample size as reported at baseline) showed that egg consumption is associated with increased risk of CHD among diabetics. The relative risk (RR) for CHD among diabetics consuming $\geq 1$ egg per day compared with those consuming $<1$ egg per week was 2.02 (95\% confidence interval [CI]: 1.05-3.87; $P$-trend=0.04) and 1.49 (95\% CI: 0.88-2.52; $P$-trend $=0.008)$ for men and women, respectively.

Tanasescu et al examined data from a prospective cohort study of 5,672 women with T2DM and found a significant association between CVD risk and dietary cholesterol, even after adjustment for other dietary fats. ${ }^{46}$ The subjects were aged 30-55 years at enrollment and had an average follow up of 10 years. Dietary cholesterol, total fat, saturated fat, polyunsaturated fatty acid (PUFA) monounsaturated fatty acid (MUFA), etc, were measured via FFQ at baseline and at follow up every 2 years. The study subjects were classified by quintile of dietary cholesterol intakes, and Cox proportional hazard models were used to estimate the RR for CVD associated with cholesterol intake. The analysis was repeated using cholesterol intake as a continuous variable, ie, the RR associated with each dietary cholesterol increase of $200 \mathrm{mg} / 1,000$ $\mathrm{kcal}$, an equivalent of dietary cholesterol from one egg. The subjects' diabetic status was determined based on a report of physician diagnosis of T2DM at age $\geq 30$ years, confirmed by reported FPG level or treatment with hypoglycemic drugs. A significant RR for CVD was observed in the highest quintile of cholesterol intake (median intake: $298.2 \mathrm{mg} / 1,000 \mathrm{kcal}$ ) relative to the first quintile (median intake: $139 \mathrm{mg} / 1,000$ kcal). The RR was 1.39 (95\% CI: 1.04-1.88; $P$-trend=0.01). In analyses using a continuous measure of dietary cholesterol, the RR of CVD for each $200 \mathrm{mg}$ cholesterol/1,000 kcal increase was 1.37 (95\% CI: $1.12-1.68 ; P$-trend $=0.003)$.

Trichopoulou et al conducted a prospective cohort study of 1,013 diabetic Greek adults treated with antidiabetic drugs. ${ }^{38}$ The subject's diabetic status was ascertained by self-report and presentation of information on antidiabetic drug use. The average follow up was 4.5 years (range 2-114 months). Egg consumption was measured via FFQ at baseline and expressed in g/day. All-cause death and CVD death were the main study outcomes. The estimated hazard ratio (HR) for CVD mortality for an increase of daily egg consumption of $10 \mathrm{~g}$ /day was 1.54 (95\% CI: 1.20-1.97).

An analysis of a prospective cohort study by Qureshi et al of 9,734 men and women, aged between 25-74 years at enrollment, who had an average follow up of 15.9 years, found a twofold increase in CAD or MI risk among diabetics (men and women combined) who consumed more than 6 eggs per week. ${ }^{14}$ Egg consumption was measured via FFQ at baseline, and subjects were classified in three groups: $<1,1-6$, and $\geq 7$ times per week (The study reported these intervals as "eggs per week"; however, the question in the FFQ used by the study expressed intake as "times per week", not "eggs per week"). The main study outcomes were hospitalization or death from stroke and CAD. In the secondary analysis of 349 subjects who had reported a physician diagnosis of diabetes mellitus, the RR for CAD associated with $>6$ eggs per week relative to $<1$ egg per week was 1.9 (95\% CI: 1.0-3.5). No association was detected between egg consumption and risk of stroke.

Djoussé and Gaziano analyzed data from a prospective study of 21,327 male health professionals, aged 40-86 years, who had an average follow up of 20 years. ${ }^{22}$ Egg consumption was measured using a FFQ, with a question on the "average frequency of consumption of eggs during past year" at baseline and every 24 months. Egg consumption status was classified in five groups: $<1,1,2-4,5-6$, and $\geq 7$ eggs per week. The study outcome measure was incident MI, stroke (as reported by participants and confirmed by review of medical records), or death. Secondary analyses investigating the association among subjects with diabetes found a statistically significant association between egg consumption and all-cause mortality but not for MI or stroke. The HRs for $\mathrm{MI}$ and stroke among diabetics consuming $\geq 7$ eggs per week compared with those consuming $<1$ egg per week were 1.06 (95\% CI: $0.43-2.63$; $P$-trend $=0.97)$ and 1.83 (95\% CI: $0.71-4.23$; $P$-trend $=0.52$ ), respectively.

Scrafford et al used data from a nationally representative prospective cohort study of 6,833 men and 8,113 women, aged $\geq 17$ years at enrollment with an average follow up of 8.9 years (women) and 8.8 years (men), to investigate the association between egg consumption and death from stroke or CHD. ${ }^{16}$ Egg consumption in the past 30 days was measured via FFQ at baseline and was classified in three categories: $<1,1-6$, and $\geq 7$ eggs per week. The secondary analyses of subjects with diabetes did not detect a significant association in CHD or stroke mortality and egg consumption 
( $\geq 7$ eggs/week) among diabetics. The subjects' diabetes status was determined by self-report of diabetes diagnosis.

Houston et al conducted a prospective study of 1,941 older adults aged 70-79 years who participated in the Health, Aging, and Body Composition Study and who had an average follow up of 9 years. ${ }^{39}$ Egg consumption was measured using a FFQ, and consumption status was classified into three groups: $<1,1-2$, and $\geq 3$ times per week. Incident CVD (confirmed nonfatal MI or stroke from hospital records and coronary deaths) was the study outcome measure. Secondary analyses of 341 diabetics found a statistically significant association between egg consumption and CVD risk. Among diabetics consuming eggs $\geq 3$ times per week compared with those consuming eggs $<1$ time per week, the HR was 5.02 (95\% CI: $1.63-15.51 ; P$-trend $<0.05)$. The subjects' diabetes status was determined using a combination of self-report, medication use, and FPG $\geq 6.99 \mathrm{mmol} / \mathrm{L}$.

Like most epidemiologic investigations, these studies have their strengths and limitations. Large cohorts and long period of follow up, with the exception of the Trichopoulou et al study, ${ }^{38}$ are the main strengths of these studies. Study limitations included a lack of control for well-established dietary confounders. Hu et al controlled for some dietary confounders but did not include, for example, whole grain or fruit and vegetable intakes; they also did not explain how the subjects' diabetic status was ascertained, and their study population (health professionals and nurses) may not be representative of the general population..$^{21}$ The Tanasescu et al study population of nurses may not be representative of the general population of women, and dietary cholesterol, rather than egg consumption, was examined in this study. ${ }^{46}$ The Trichopoulou et al study had several limitations, including the lack of consideration for important dietary factors (eg, total fat, saturated fat, PUFA, MUFA), relatively short follow up, and ascertainment of T2DM status based on self-reports and currently taking antidiabetic drugs. ${ }^{38}$ The Qureshi et al study population is representative of the general population; however, the study failed to control for potential dietary confounders and relied on self-report of diabetic status. ${ }^{14}$ The Djoussé and Gaziano study also did not control for dietary confounders, including fat, saturated fat, cholesterol, whole grain and fruit intake; its study population (physicians) may not be representative of the general male population; and the study did not identify how T2DM status was ascertained. ${ }^{22}$ The Houston et al study's strength included ascertainment of T2DM status; however, it did not control for other dietary confounders, including fat, MUFA, and PUFA, and the study population was relatively older than the general
US population..$^{39}$ A study population representative of the general population and control for dietary confounders were among the main study strengths in the Scrafford et al study; however, the estimates of dietary confounders were based on short-term dietary recall, the number of diabetic cases was small, and T2DM status was based on self-report. ${ }^{16}$

In general, there are several inconsistencies between these studies that present significant challenges in conducting a meta-analysis, including:

- Outcome definition: some studies defined the outcome as CVD, others defined the outcomes as stroke, CHD, and/or MI; further, some studies evaluated CVD mortality, while others evaluated CVD and mortality

- Measurement of exposure (egg consumption): some studies measured egg amount in $\mathrm{g} /$ day, others measured number of eggs per week or times per week, and some used cholesterol intake instead of eggs. There were differences in categories of egg consumption for which HRs were reported. Further, it is unclear whether eggs in mixed dishes were accounted for in these studies

- Differences in how T2DM status was ascertained

- Inconsistent reporting of diabetes treatment: some studies excluded T2DM who were taking insulin, but it is not clear whether or not this was the case for all studies

- Differences in control for confounding variables

- Differences in follow-up time.

Despites these limitations, three meta-analyses quantifying the association between egg consumption and CVD risks among diabetics have been published. ${ }^{18,19,71}$ Rong et a ${ }^{18}$ investigated the potential dose-response association between egg consumption and risk of CHD and stroke among the general population using data from four studies, ${ }^{14,16,21,22}$ and among diabetics subjects in a subgroup analysis using three studies. ${ }^{14,16,22}$ Based on a summary risk estimate comparing the highest with the lowest egg consumption, Rong et a ${ }^{18}$ reported a significant increased risk of CHD ( $R R=1.54$ [95\% CI: 1.14-2.09]), a borderline significant reduction in risk for hemorrhagic stroke ( $\mathrm{RR}=0.75$ [95\% CI: $0.57-0.99]$ ), and no association between egg intake and ischemic $(\mathrm{RR}=0.91$ [95\% CI: $0.82-1.01])$ or total stroke $(\mathrm{RR}=0.80$ [95\% CI: 0.29-2.15]). In another subgroup analysis of diabetics by $\mathrm{Li}$ et al ${ }^{71}$ risk estimates comparing the highest with the lowest egg consumption categories were pooled from five studies ${ }^{14,16,21,39,41}$ and resulted in a significantly higher overall risk of CVD among diabetics $(\mathrm{RR}=1.83$ [95\% CI: $1.42-2.37]) .{ }^{71}$ Finally, in a meta-analysis of prospective cohort studies, Shin et a ${ }^{19}$ estimated a pooled HR of 1.69 (95\% CI: 1.09-2.62) for incident CVD among diabetics, 
based on four studies. ${ }^{14,21,39,46}$ In light of the above identified inconsistencies between the studies and potential challenge for conducting a meta-analysis, we noted that the study inclusion or exclusion criteria were not clear or consistent among the three published meta-analyses. For example, Shin et al ${ }^{19}$ excluded the female cohort from the $\mathrm{Hu}$ et $\mathrm{al}^{21}$ study, for whom there was not a significant association observed (RR of CVD in diabetes patients when comparing high with low egg consumption was 1.49 [95\% CI: 0.88-2.52]), while the male cohort was included ( $\mathrm{RR}=2.02$ [95\% CI: $1.05-3.88]$ ). In contrast, $\mathrm{Li}$ et $\mathrm{al}^{71}$ included the $\mathrm{Hu}$ et $\mathrm{al}^{21}$ female cohort and assigned this cohort the second highest weight. All three meta-analyses were limited to a small number of observational studies, and the results in diabetics should be interpreted with caution. ${ }^{18,19,71}$ In conclusion, while these meta-analyses aim to fill the knowledge gap surrounding egg consumption and CVD in patients with diabetes, the limitations in the analysis and underlying data need to be considered before drawing any broad conclusions.

\section{Egg consumption and diabetes risk}

A small number of recent studies have been conducted to evaluate the direct relationship between egg consumption and diabetes risk. Nine of these studies evaluated egg consumption, and two evaluated dietary patterns that included eggs. Five of the nine studies (one study contains two investigations within one publication) found a statistically significant association between diabetes risk and egg consumption. ${ }^{42,44,63,65}$ Shi et al found a significant association among women but not among men, ${ }^{42}$ while Ericson et al observed a significant association among men but not women. ${ }^{65}$ Two studies did not find a statistically significant association, but one referred to the older age of the study population and their lower egg intake, ${ }^{41}$ while the other was based on self-reported diabetes and therefore, may have had significant reporting bias in the measurement of the outcome. ${ }^{64} \mathrm{~A}$ third study also reported no association between egg consumption and T2DM, comparing the highest versus the lowest quartile of egg consumption ( $<4$ eggs/week vs $>1$ egg/week) after adjusting for confounders (odds ratio [OR] $=0.7$ [95\% CI: 0.3-1.7]), among 15,956 subjects in a Mediterranean cohort. ${ }^{66}$ However, the text of the full article is in Spanish, and therefore, this study was excluded from further evaluation. Two studies found significant associations between dietary scores representing dietary patterns that included egg consumption and T2DM, ${ }^{43,45}$ while Ericson et al observed a significant association between overall protein intake and risk of T2DM. ${ }^{65}$ Summaries of these studies are in Table 2 and are briefly described here.
Djoussé et al used data collected on 20,703 male physicians and 36,295 female health professionals from two completed randomized trials, The Physicians' Health Study and the Women's Health Study, respectively, to assess the association between egg consumption and T2DM risk. ${ }^{40}$ The mean ages at enrollment were 53.5 and 54.5 years, with average follow up of 20 and 11.7 years for men and women, respectively. Egg consumption was measured using a FFQ at baseline for both men and women and every 24 months for men, and subjects were classified into six intake groups: no egg, $<1,1,2-4,5-6$, and $\geq 7$ eggs per week. T2DM status was obtained based on self-report for men, and self-report together with validation using telephone interviews, supplemental questionnaires, and review of medical records for women. A secondary analysis stratified subjects by hypercholesterolemia and, for women, energy from carbohydrates. The study concluded that consumption of at least one egg per day was significantly associated with an increased risk of T2DM. The HR for $\geq 7$ eggs per week was 1.58 (95\% CI: 1.25-2.01) and 1.77 (95\% CI: 1.28-2.43) for men and women, respectively compared with those reporting no egg consumption.

Djoussé et al conducted a prospective study to assess the association between egg consumption and the incidence of T2DM among older adults. ${ }^{41}$ The mean age at enrollment was 73.2 years for men and was 72.1 years for women, and the average follow up was 11.3 years. Egg consumption was measured via FFQ, and subjects were classified into one of five intake categories: never, $<1 /$ month, $1-3 /$ month, $1-4 /$ week, and almost every day. T2DM status was determined based on the use of antidiabetic drugs or FPG levels. Cox proportional hazard models were used to compute the HR for T2DM associated with egg consumption. The analysis did not detect an increased risk of T2DM with consumption of eggs. The HR (CI) for T2DM for subjects consuming eggs almost daily (reference group: nonconsumers) was 1.81 (95\% CI: $0.77-4.22$ ) for men and was 0.38 (95\% CI: 0.10-1.37) for women.

In a population-based prospective cohort study in Sweden, Ericson et al examined the relationship between the components of dietary macronutrient intake and T2DM. ${ }^{65}$ Data were included from 27,140 individuals aged 45-74 years, with a mean follow up of 12 years, in the Malmo Diet and Cancer Cohort. Egg intake was assessed using an interviewbased, modified 7-day diet history method combining a diary with a 168-item semiquantitative food-frequency questionnaire. There were 1,709 incident cases of T2DM identified over 320,703 person-years of follow up, from 


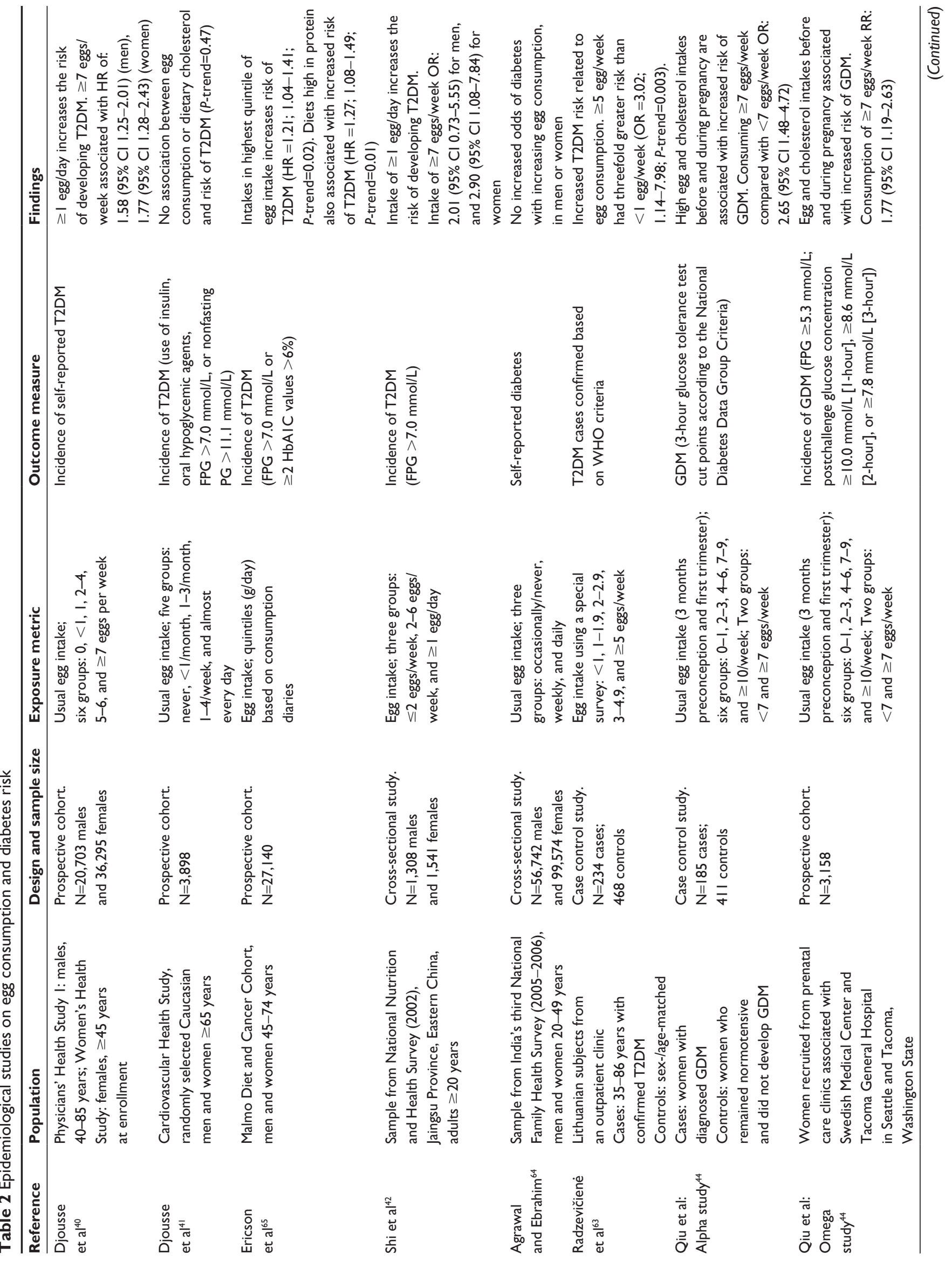




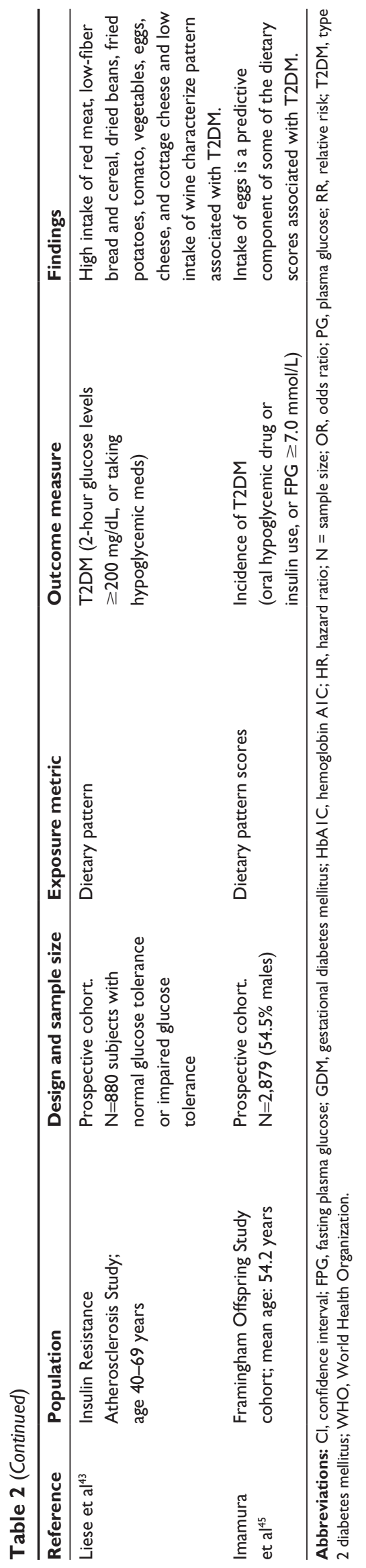

national registries requiring a physician's diagnosis, according to the criteria of $F P G \geq 7.0 \mathrm{mmol} / \mathrm{L}$, fasting whole blood glucose $\geq 6.1 \mathrm{mmol} / \mathrm{L}$ measured at two different occasions, or at least two $\mathrm{HbA} 1 \mathrm{C}$ values $>6.0 \%$. Cox proportional hazard regression models were used to estimate the HRs of T2DM with quintiles of daily egg intake (grams). Higher quintiles of egg intake were associated with an increased risk of T2DM (HR $=1.21 ; 95 \%$ CI: $1.04-1.41 ; P$-trend=0.02) among the total population, in multivariate modeling. When the analysis was stratified by sex and controlled for all factors including body mass index (BMI), the association in women was not significant. The association in men was only significant among the highest quintile of egg consumers ( $\mathrm{HR}=1.32$; 95\% CI: 1.07-1.63), but the increasing trend was borderline significant $(P$-trend $=0.05)$. The researchers also found a significant association between protein intake and T2DM among the total population ( $\mathrm{HR}=1.27 ; 95 \% \mathrm{CI}$ : $1.08-1.49$ ), but the association only remained significant among women in the sex-stratified analysis (HR $=1.30 ; 95 \%$ CI: 1.03-1.64; $P$-trend $=0.07)$.

Radzevičienè et al conducted a case-control study to examine the role of eggs and T2DM risk among Lithuanian subjects. ${ }^{63}$ The study was carried out at an outpatient clinic and included 234 cases, aged 35-86 years, with a newly confirmed diagnosis of T2DM according to WHO criteria. A total of 468 controls (sex- and \pm 5 years age-matched) were also recruited from the same clinic. Egg intake was obtained using a special questionnaire (details not provided). Conditional logistic regression was used to evaluate the OR for T2DM in relation to egg consumption. The multivariate analysis showed that the risk of T2DM increased among subjects who consumed $\geq 5$ eggs/week compared with subjects eating $<1$ egg/week (OR =3.02; 95\% CI: 1.14-7.98).

Qiu et al reported on two studies assessing the association between risk of gestational diabetes mellitus (GDM) and maternal egg consumption. ${ }^{44}$ The first study, the Omega study, was a prospective study of 3,158 women obtaining prenatal care. The mean age at enrollment was 32.7 years, and egg consumption in the 3 months preconception and during the first pregnancy trimester was measured via FFQ. Subjects were classified in six groups: $0, \leq 1,2-3,4-6,7-9$, and $\geq 10$ eggs per week. The analysis was repeated using two egg consumption categories: $<7$ and $\geq 7$ eggs per week. The study outcome was GDM, defined based on FPG levels and oral glucose tolerance test. Generalized linear models using a log-link function were used to estimate the RR for the association of GDM with maternal egg consumption. The models were adjusted for total energy, age, race/ethnicity, 
prepregnancy BMI, physical activity, intake of meat, fiber, vitamin C, and saturated fat. Other factors (smoking, family history of diabetes, daily fruit, vegetable, and cholesterol intake) were investigated and found not to affect the association between maternal egg intake and GDM and were not included in the final model. The RR for the association of GDM with a maternal egg consumption of $\geq 10$ eggs per week (reference group: nonconsumers) was 2.52 (95\% CI: $1.11-5.72 ; P$-trend $=0.008)$. In the analysis using a dichotomized classification of egg consumption, the RR for the association of GDM with $\geq 7$ eggs per week was 1.77 (95\% CI: 1.19-2.63).

The second study reported by Qiu et al, the Alpha Study, was a case-control study designed primarily to examine the epidemiology of preeclampsia, but the study also recruited women with GDM. ${ }^{44}$ A total of 185 GDM cases were included. The controls included 411 study subjects who did not develop GDM and remained normotensive. The mean age for the cases was 32.9 years, and for the controls, the mean age was 31.5 years. Egg consumption was measured via FFQ (including portion sizes), assessing dietary intake in the three months preconception and during pregnancy. Subjects were classified in six groups: $0, \leq 1,2-3,4-6,7-9$, and $\geq 10$ eggs per week. GDM was assessed via a 3 -hour glucose tolerance test. Multivariate logistic regression models were used to estimate the OR for GDM and egg consumption. The models were adjusted for the following confounders: total energy, age, race/ethnicity, prepregnancy BMI, physical activity, smoking, family history of diabetes, intake of meat, fiber, vitamin $C$, and saturated fat. The analysis was repeated using two egg-consumption categories: $<7$ and $\geq 7$ eggs per week. The primary analyses detected a significant increased risk of GDM with consumption of eggs. The OR for GDM associated with $\geq 10$ eggs per week (reference group: nonconsumers) was 2.76 (95\% CI: $1.03-7.43 ; P$-trend $=0.005)$. In the analysis using a dichotomized classification of egg consumption, the OR for GDM associated with $\geq 7$ eggs per week was 2.65 (95\% CI: 1.48-4.72).

Shi et al conducted a cross-sectional study of 1,308 men and 1,541 women, aged $\geq 20$ years, from a nationally representative sample in Jiangsu, People's Republic of China. ${ }^{42}$ Egg consumption was measured via a FFQ, with estimated portion sizes, and subjects were classified in three intake groups: $\leq 2$ eggs/week, 2-6 eggs/week, and $\geq 1$ eggs/day. Incident T2DM was based on FPG $>7.0 \mathrm{mmol} / \mathrm{L}$. Logistic regression models were used to compute the OR for the association of T2DM with egg consumption, with adjustment for the following confounders: age, energy intake, education, smoking, sedentary activity, family history of diabetes, and BMI. A statistically significant increased risk of T2DM with consumption of egg, for women and for the total population, was found; the increase in men was not statistically significant. The OR associated with intake of $\geq 1$ eggs/day was 2.01 (95\% CI: 0.73-5.55; $P$-trend $=0.335$ ) for men and was 2.90 (95\% CI: $1.08-7.84 ; P$-trend $=0.033)$ for women.

In a cross-sectional study of 99,574 women and 56,742 men aged 20-49 years, from India's third National Family Health Survey (NFHS-3) (2005-2006), Agrawal and Ebrahim examined the distribution of self-reported diabetes and its association with modifiable risk factors. ${ }^{64}$ Egg consumption was categorized as daily, weekly, occasionally, or never, based on the response to the question "How often do you yourself consume eggs?". ${ }^{64}$ For purposes of analysis, the occasional/never egg consumers were grouped together and used as the reference group. In a crude analysis, there was an increased odds of diabetes among the weekly and daily egg consumers, but this association was no longer significant after the adjustment for age; socioeconomic status; BMI; activity level; smoking; and dietary factors, including milk, fruit/vegetables, pulses/beans, fish, meat/chicken, and alcohol consumption (OR for daily vs occasionally/never egg consumption was 1.06 [95\% CI: 0.90-1.26] and 1.11 [95\% CI: 0.93-1.31] for women and men, respectively).

Liese et al investigated the association between plasminogen activator inhibitor-1 (PAI-1), fibrinogen, and T2DM (based on 2-hour glucose levels) and dietary patterns, in a prospective study of 880 subjects, aged 40-69 years, with normal or impaired glucose tolerance. ${ }^{43}$ The average follow up was 5.2 years. Usual intakes were assessed via a 1-year semiquantitative FFQ. Dietary patterns were derived using reduced-rank regression, and logistic regression was used to model T2DM versus diet scores. The models included the following confounders: age, sex, race, clinic, parental history of diabetes, glucose tolerance status at baseline, energy expenditure, smoking, energy intake, insulin sensitivity, acute insulin response, and BMI. The analysis identified a food pattern predictive of T2DM that was characterized by a high intake of red meat, low-fiber bread and cereal, dried beans, fried potatoes, tomato, vegetables, eggs, cheese, and cottage cheese, and a low intake of wine. The OR for the association of T2DM with the fourth quartile of the food pattern score (reference group: first quartile) was 4.51 (95\% CI: 1.60-12.69; $P$-trend $=0.0173)$.

Imamura et al investigated the association between T2DM (based on antidiabetes drug use or a FPG $\geq 126 \mathrm{mg} / \mathrm{dL}$ ) and 
dietary patterns in a prospective study of 2,879 subjects (mean age 54.2 years) from the Framingham Offspring Study. ${ }^{45}$ The study follow-up period was 7 years. Usual intakes were assessed via a FFQ. Dietary patterns were derived using reduced-rank regression, and multivariate Cox proportional hazard regression models were used to estimate the HR for T2DM associated with quartiles of the dietary pattern scores. The models included the following confounders: age, sex, parental history of diabetes, treatment for elevated blood pressure (BP), caloric intake, and weight change. Scores associated with dietary patterns from three studies (the Nurses' Health Study, the European Prospective Investigation into Cancer, and the Whitehall II study) were used in this study. The dietary patterns predictive of T2DM were not consistent across the studies. High intakes of soft drinks, meat and processed meat, and refined grains were common components of all scores. Eggs, French-fried potatoes, and alcohol were predictive in some but not others. The strongest association found was based on the food pattern score identified by the Nurses' Health Study, for which the HR for T2DM for continuous increase of the dietary pattern score was 1.44 (95\% CI: $1.25-1.66$ ), and the HR for the association of T2DM with the fourth quartile of the food pattern score (reference group: first quartile) was 4.14 (95\% CI: 2.45-6.99).

As expected, these studies have strengths and limitations. The Djoussé et al study strengths included its large cohort and long follow up; however, the study had several limitations, including a study population that may not be representative of the general US population and the lack of control for potential dietary confounders (ie, intake of fat, saturated fat, cholesterol, whole grains, carbohydrates, fruit and vegetables, and, in the men's data analyses, family history of diabetes). ${ }^{40}$ The study population was relatively older and had low reported egg consumption. ${ }^{41}$

The Shi et al and Agrawal and Ebrahim studies included a relatively large sample; however, both studies were cross sectional and did not adjust for several variables found to be associated with egg consumption, including: protein, fat, and carbohydrate intake or other dietary factors known to be associated with diabetes, eg, saturated fat intake. .2,64 $^{2}$ Shi et al also did not adjust for active commuting, residence, or income. ${ }^{42}$ Further, the Agrawal and Ebrahim study was based on self-report of diabetes, with no physician's confirmation of diagnosis. ${ }^{64}$ The Radzevičienè et al study was a small case-control study with several limitations, including the lack of accounting for other dietary factors and reliance on self-reported intake obtained from a questionnaire of unknown quality. ${ }^{63}$

The Qiu et al studies evaluated the risk of GDM, rather than T2DM. These studies had relatively large sample sizes but did not adjust for dietary cholesterol (from sources other than eggs) or several other dietary variables that were significantly associated with egg consumption (eg, whole grain, PUFA, MUFA, and n-3 fatty acid intake in the Omega study; or parity, history of hypertension, family history of hypertension, and intakes of cholesterol from sources other than eggs, PUFA, MUFA, trans fat, n-3 fatty acids, and fruit intake, in the Alpha study). ${ }^{44}$

The study by Ericson et al analyzed data from a large study with long follow up and benefited from highly validated dietary methods and the ability to exclude individuals with reported dietary changes in the past. The multivariate models used in the study were adjusted for potential dietary confounders, including fiber-rich bread and cereals, fruit and vegetables, and fat intake but did not include an adjustment for dietary cholesterol intake from sources other than meat and eggs. However, the authors noted that the marginal significance observed between egg consumption and T2DM may have been due to limitations in the statistical power, especially in the sex-stratified analyses. ${ }^{65}$

The Leise et al and Imamura et al studies used a multifactorial approach for defining risk factors; however, the HRs were derived for diet pattern scores, not necessarily for specific foods, and thus could not be used to express the excess risk of T2DM associated with increased egg consumption. ${ }^{43,45}$ In addition, the Imamura et al study used dietary patterns extracted from other studies and found inconsistencies in the composition of these patterns across studies, in particular with respect to the contribution of eggs to the pattern scores. ${ }^{45}$

Overall, the following inconsistencies between these studies present significant challenges for conducting a metaanalysis and limit the interpretation of results:

- Differences in study design: some were case-control studies, while others were prospective cohort studies

- Outcome differences: the outcome in the two Qui et al studies was GDM, while the other studies focused on T2DM

- Differences in how T2DM was measured: some studies relied on self-reports, others relied on self-reports and follow-up questionnaires, while still others required actual confirmation based on FPG

- Difference in the "exposure" variable: eight of the studies modeled the association between T2DM and eggs directly and two of the studies (Imamura et $\mathrm{a}^{45}$ and Liese et $\mathrm{al}^{43}$ ) 
investigated the association of dietary scores representing dietary patterns (which included eggs) and T2DM

- Difference in the age of the study populations

- Difference with respect to the other diabetes risk factors they controlled for

- Difference in follow-up time.

Despite these limitations, Li et $\mathrm{al}^{71}$ and Shin et $\mathrm{al}^{19}$ quantified the risk of T2DM associated with egg consumption as part of the meta-analyses of prospective cohort studies described previously. Both sets of analyses showed a significant increased risk of T2DM when comparing the highest ( $\geq 1 \mathrm{egg} /$ day) to the lowest ( $<1 \mathrm{egg} /$ week or never) category of egg consumption. Pooled incident risk estimates ranged from 1.42 (95\% CI: $1.09-1.86)$ based on five cohorts ${ }^{19}$ to 1.68 (95\% CI: $1.41-2.00)$ based on seven cohorts. ${ }^{71}$ Again, the underlying data and methodology in the individual cohorts included in these meta-analyses need to be considered as well as the limited number of available studies upon which these conclusions are based.

\section{Biomarkers of $\mathrm{CHD} /$ diabetes risk factors and egg consumption}

The published literature on the role of dietary cholesterol from both egg and non-egg sources and biomarkers of CHD risk, such as lipoproteins, among healthy individuals is extensive and has previously been reviewed. The overall evidence from human studies has documented the lack of effect of dietary cholesterol on lipoprotein levels among healthy individuals. ${ }^{72,73}$ On the other hand, while there is a possibility that diabetics transport cholesterol differently than healthy individuals, providing a possible explanation for the apparent observed association between egg consumption and CHD risk among diabetics, ${ }^{21}$ the biological mechanism underlying this relationship remains elusive. In the current review, we conducted a focused literature search to identify experimental studies that examined whether egg consumption is associated with alterations in the biomarkers of CVD risk among diabetics or subjects with CHD/T2DM risk factors, such as MetS and/or insulin resistance.

A limited number of studies were found, including six studies that were conducted on diabetics (Table 3). Of these six studies, eggs were the primary sources of dietary cholesterol in three of the studies. ${ }^{47-49}$ In the trial conducted by Arora et al, no statistical significant change in serum total cholesterol, HDL, LDL, or triglycerides (TAG) was found, within and across the study groups of healthy controls and Type I and II diabetic subjects, after a single dose of $800 \mathrm{mg}$ egg cholesterol. ${ }^{47}$ The Romano et al trial found a significant increase in LDL and ratio of LDL/HDL in Type I diabetics when fed with $800 \mathrm{mg}$ egg cholesterol over a period of 3 weeks. ${ }^{48}$ On the contrary, the Pearce et al trial found statistically significant decreases in weight, total cholesterol, TAG, non-HDL-C, apolipoprotein B, HbA1C, FPG, insulin, and BP among T2DM patients after 12 weeks of hypoenergetic high-protein diets with either low or high cholesterol (from egg supplementation). ${ }^{49}$ Eggs were also part of a diet (the "Paleolithic diet") in two studies conducted on T2DM subjects. ${ }^{50,51}$ In the Lindeberg et al trial, T2DM subjects on a Paleolithic diet had better improvement in FPG than did those on a Mediterranean diet. ${ }^{51}$ Similarly, T2DM subjects in the Jönsson et al trial who were on a Paleolithic diet also had lower HbA1C, TAG, diastolic BP, weight, BMI, waist circumference (WC), and higher HDL-C than did those on the diabetes diet. ${ }^{50}$ In the trial by Taggart et al, extremely high doses of cholesterol ( $1 \mathrm{~g} /$ day and not from egg sources) were given to T2DM subjects. ${ }^{58}$ Following the challenge, there was a tenfold increase in very low-density lipoprotein (VLDL) and apolipoprotein B48 in diabetic subjects compared with a threefold increase in healthy controls.

There were six experimental trials that were conducted on nondiabetic individuals who had risk factors for CHD/T2DM (Table 4). Of these six studies, the study by Knopp et al was conducted on hypercholesterolemic or combined hyperlipidemic subjects who were fed either 2 eggs a day or egg substitutes for 12 weeks. ${ }^{52}$ This study found that in the egg-fed group, LDL-C significantly increased among hyperlipidemic subjects; however, HDL-C was also significantly increased among both the hypercholesterolemic and combined hyperlipidemic subjects. In another study by Knopp et al conducted on insulin sensitive, insulin resistant (IR), obese IR and lean IR subjects, it was found that feeding 4 eggs a day for 1 month led to statistically significant increases in LDL-C in insulin sensitive and IR subjects and statistically significant increases in HDL-C in insulin sensitive, IR, and obese IR subjects. ${ }^{53}$ The trial by Tannock et al found increases relative to baseline in C-reactive protein (CRP), serum amyloid A (SAA), and non-HDL-C among lean IR subjects after 1 month of feeding of 4 eggs a day. ${ }^{54}$ One study (Mutungi et al) was conducted on male subjects, some with MetS at baseline, and found no differences in serum lipids among the subjects who were fed either 3 whole eggs a day or egg substitute for 12 weeks. ${ }^{55}$ Another study by Amini et al, albeit cross-sectional in nature, was conducted on 425 individuals with impaired glucose tolerance in which egg intake was evaluated as part of a Western dietary pattern. ${ }^{57}$ This study found the Western dietary pattern to be associated with greater odds of having 
Table 3 Clinical studies on CHD risk factors and egg consumption among diabetics

\begin{tabular}{|c|c|c|c|c|}
\hline Study & Design, aim, and sample size & Treatment and duration & Outcome measures & Findings \\
\hline $\begin{array}{l}\text { Arora } \\
\text { et } \mathrm{al}^{47}\end{array}$ & $\begin{array}{l}\text { Single dietary challenge to study } \\
\text { lipoprotein profile following egg } \\
\text { cholesterol challenge. } n=13 \\
\text { controls, } n=10 \text { diabetic patients }\end{array}$ & $\begin{array}{l}\text { One feeding of } 800 \mathrm{mg} \text { of } \\
\text { cholesterol derived from egg } \\
\text { and } 150 \mathrm{~mL} \text { sweetened milk }\end{array}$ & $\begin{array}{l}\text { Serum TC, HDL, } \\
\text { LDL, and TAG }\end{array}$ & $\begin{array}{l}\text { No SS changes detected within } \\
\text { groups or across study groups }\end{array}$ \\
\hline $\begin{array}{l}\text { Taggart } \\
\text { et a }\left.\right|^{58}\end{array}$ & $\begin{array}{l}\text { Dietary intervention to study } \\
\text { relationship between fasting } \\
\text { and postprandial intestine- } \\
\text { derived atherogenic Apo B48 } \\
\text { in T2DM subjects. } n=10 \text { cases, } \\
n=10 \text { controls }\end{array}$ & $\begin{array}{l}\text { Test meal with I g added } \\
\text { cholesterol. Egg yolk was } \\
\text { not used as a source } \\
\text { of cholesterol. Two single } \\
\text { meals given I week apart }\end{array}$ & $\begin{array}{l}\text { Serum VLDL, LDL, } \\
\text { chylomicron, blood } \\
\text { glucose, HbAIC, } \\
\text { and insulin }\end{array}$ & $\begin{array}{l}\text { A tenfold increase in VLDL Apo B48 } \\
\text { in diabetics compared with a threefold } \\
\text { increase in controls }(P<0.00 \mathrm{I}) \\
\text { postchallenge. VLDL Apo BI00 similar } \\
\text { between groups following challenge. } \\
\text { Accounting for E3/E3 genotype did not } \\
\text { change results }\end{array}$ \\
\hline $\begin{array}{l}\text { Romano } \\
\text { et } \mathrm{al}^{48}\end{array}$ & $\begin{array}{l}\text { Double-blind, randomized } \\
\text { placebo control, sequential } \\
\text { crossover study of the effects } \\
\text { of cholesterol supplementation } \\
\text { on plasma lipid lipoprotein } \\
\text { subclasses in normolipidemic } \\
\text { type I diabetics. } \mathrm{N}=10 \text { patients, } \\
\mathrm{n}=\mathrm{II} \text { controls }\end{array}$ & $\begin{array}{l}\text { Cholesterol supplementation } \\
(800 \mathrm{mg} / \text { day) from egg yolk } \\
\text { or placebo }\end{array}$ & $\begin{array}{l}\text { VLDL (subtypes I, } 2 \text {, } \\
\text { and } 3 \text { ) and composition, } \\
\text { LDL (subtypes I, 2, } \\
\text { and } 3 \text { ) and composition, } \\
\text { HDL (subtypes } 2 \mathrm{~b}, 2 \mathrm{a}, 3 \mathrm{a} \text {, } \\
\text { and } 3 \mathrm{~b} \text { ) and composition }\end{array}$ & $\begin{array}{l}\text { SS increase in total LDL in patients } \\
\text { but not controls following cholesterol } \\
\text { intake. No effect on HDL in patients } \\
\text { after cholesterol feeding, and } \\
\text { increased concentration of HDL2a } \\
\text { subtype (but not other subtypes) in } \\
\text { controls. In patients' LDL, the particle } \\
\text { mass increased with cholesterol } \\
\text { feeding, but not in controls. No } \\
\text { changes in VLDL in either group } \\
\text { following cholesterol feeding }\end{array}$ \\
\hline $\begin{array}{l}\text { Lindeberg } \\
\text { et } \mathrm{al}^{51}\end{array}$ & $\begin{array}{l}\text { Randomized, controlled } \\
\text { intervention; male patients with } \\
\text { ischemic heart disease, either } \\
\text { glucose intolerance or T2DM. } \\
\mathrm{n}=15 \text { on Mediterranean-like } \\
\text { diet, } \mathrm{n}=14 \text { on Paleolithic diet }\end{array}$ & I2-week controlled diet & $\begin{array}{l}\text { Plasma glucose; } \\
\text { body weight changes }\end{array}$ & $\begin{array}{l}\text { Plasma glucose decreased in the } \\
\text { Paleolithic group by } 26 \% \text {, whereas } \\
\text { in the Mediterranean group, it only } \\
\text { decreased by } 7 \% \text {, independent of } \\
\text { changes in WC }\end{array}$ \\
\hline $\begin{array}{l}\text { Jönsson } \\
\text { et a }\left.\right|^{50}\end{array}$ & $\begin{array}{l}\text { Randomized crossover pilot } \\
\text { study comparing the effects of } \\
\text { a Paleolithic diet and a diabetes } \\
\text { diet in T2DM patients. } \\
\mathrm{n}=10 \text { men, } 3 \text { women }\end{array}$ & $\begin{array}{l}\text { Paleolithic diet; egg limited } \\
\text { to I egg/day; diabetes diet: } \\
3 \text { months per diet then } \\
\text { crossover; total duration } \\
6 \text { months }\end{array}$ & $\begin{array}{l}\text { HbAIC, TAG, DBP, } \\
\text { weight, BMI, WC, } \\
\text { and HDL-C }\end{array}$ & $\begin{array}{l}\text { Paleolithic diet (as compared with the } \\
\text { diabetes diet) resulted in lower mean } \\
\text { HbAIC, TAG, DBP, weight, BMI, } \\
\text { WC, and higher mean HDL-C }\end{array}$ \\
\hline $\begin{array}{l}\text { Pearce } \\
\text { et al }{ }^{49}\end{array}$ & $\begin{array}{l}\text { Parallel, randomized, matched } \\
\text { dietary intervention to study } \\
\text { the effect of a hypoenergetic } \\
\text { HPHchol compared with a } \\
\text { hypoenergetic HPLchol on } \\
\text { plasma lipids, glycemic control, } \\
\text { and cardiovascular risk factors } \\
\text { in T2DM subjects. N=3I on } \\
\text { HPHchol, } n=34 \text { on HPLchol }\end{array}$ & $\begin{array}{l}\text { HPHchol: } 590 \mathrm{mg} \\
\text { cholesterol; HPLchol: } \\
213 \mathrm{mg} \text { cholesterol by egg } \\
\text { supplementation; I } 2 \text { weeks } \\
\text { of hypoenergetic high protein } \\
\text { diet with either low or high } \\
\text { cholesterol }\end{array}$ & $\begin{array}{l}\text { TC, TAG, LDL, HDL, } \\
\text { apo-B, CRP, FPG, 2-hour } \\
\text { glucose, serum insulin, } \\
\text { homocysteine, HbAIC, } \\
\text { SBP, DBP, lutein, folate, } \\
\text { vitamin BI2, alpha } \\
\text { carotene }\end{array}$ & $\begin{array}{l}\text { SS decreases in weight, total } \\
\text { cholesterol, TAG, non-HDL-C Apo B, } \\
\text { HbAIC, FPG, and insulin, and SBP } \\
\text { and DBP in both groups. LDL-C and } \\
\text { homocysteine unchanged in both } \\
\text { groups following the hypoenergetic } \\
\text { high-protein diet. HDL-C, plasma } \\
\text { folate, and lutein increased in the high } \\
\text { cholesterol but not the low-cholesterol } \\
\text { group following the intervention }\end{array}$ \\
\hline
\end{tabular}

Abbreviations: Apo, apolipoprotein; BMI, body mass index; HbAIC, hemoglobin AIC; CHD, coronary heart disease; CRP, C-reactive protein; DBP, diastolic blood pressure; FPG, fasting blood glucose; HDL, high-density lipoprotein; HDL-C, high-density lipoprotein cholesterol; HPHchol, high-protein high-cholesterol diet; HPLchol, high-protein low-cholesterol diet; LDL, low-density lipoprotein; LDL-C, low-density lipoprotein cholesterol; $n=$ sample size; SBP, systolic blood pressure; SS, statistically significant; T2DM, Type 2 diabetes mellitus; TAG, triglycerides or triacylglycerols; TC, total cholesterol; VLDL, very low-density lipoprotein; WC, waist circumference.

an increase in TAG and BP. Four articles reported on a randomized, single-blind, placebo-controlled, parallel-designed 12-week dietary intervention study, in 37 adults aged $30-70$ years with MetS on a carbohydrate-restricted diet $(<30 \%$ energy) fed either 3 whole eggs/day (the "EGG" group, $\mathrm{N}=20$ ) compared with a yolk-free egg substitute (the "SUB" group, $\mathrm{N}=17) \cdot{ }^{67-70}$ Andersen et al found a reduction in the HDL-TAG content and an increase in the macrophage cho- lesterol efflux in the EGG group compared with the SUB group, among subjects with normal baseline HDL-C. ${ }^{67}$ Results of this intervention trial further reported increases in HDL-C and large HDL particles and a reduction in VLDL and medium VLDL particles in the EGG compared with the SUB group $(P<0.05){ }^{68}$ along with reductions in markers of inflammation (SAA and plasma tumor necrosis factor $[\mathrm{TNF}]-\alpha) .{ }^{69}$ Blesso et al also reported overall reductions in 


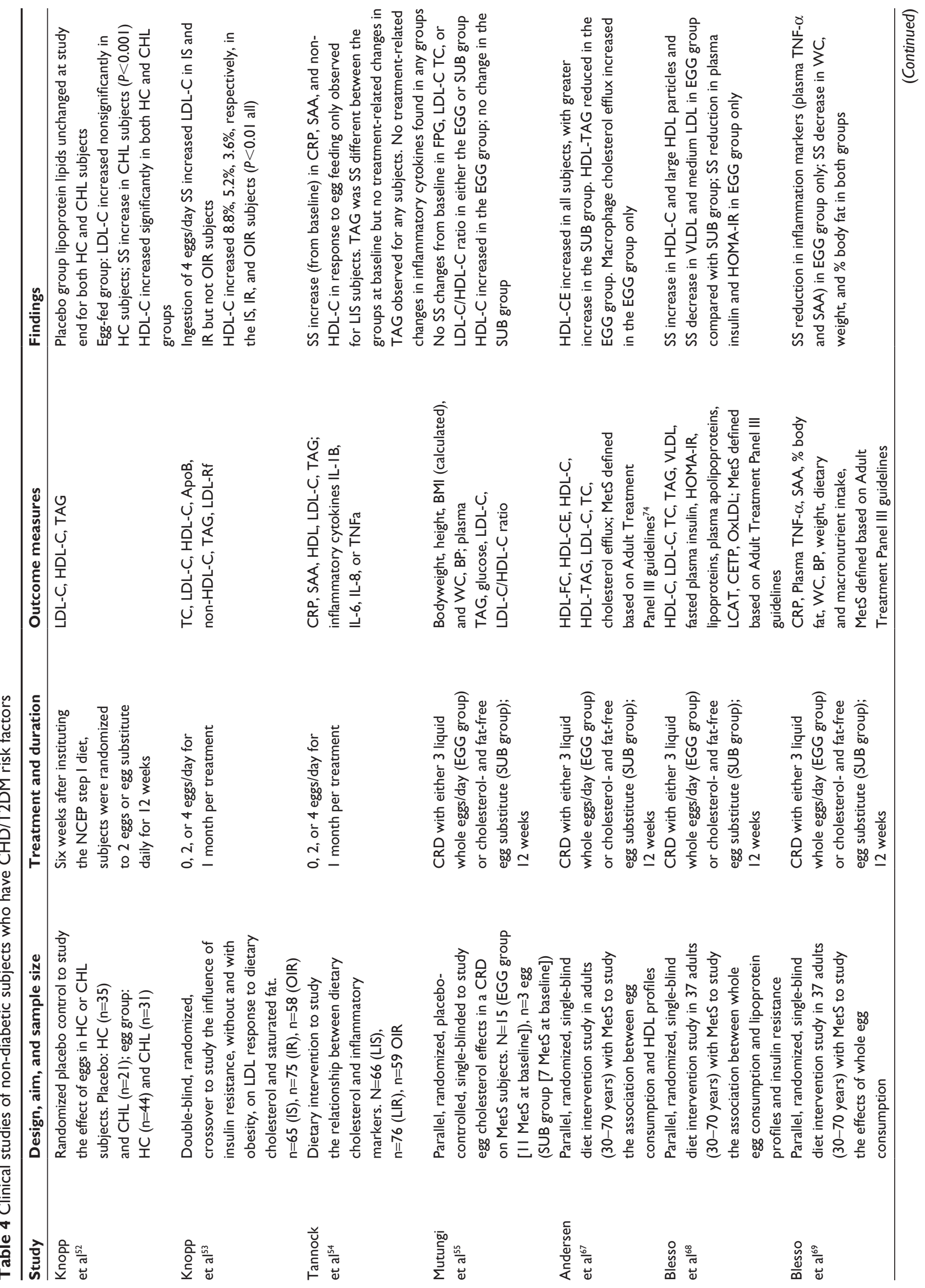




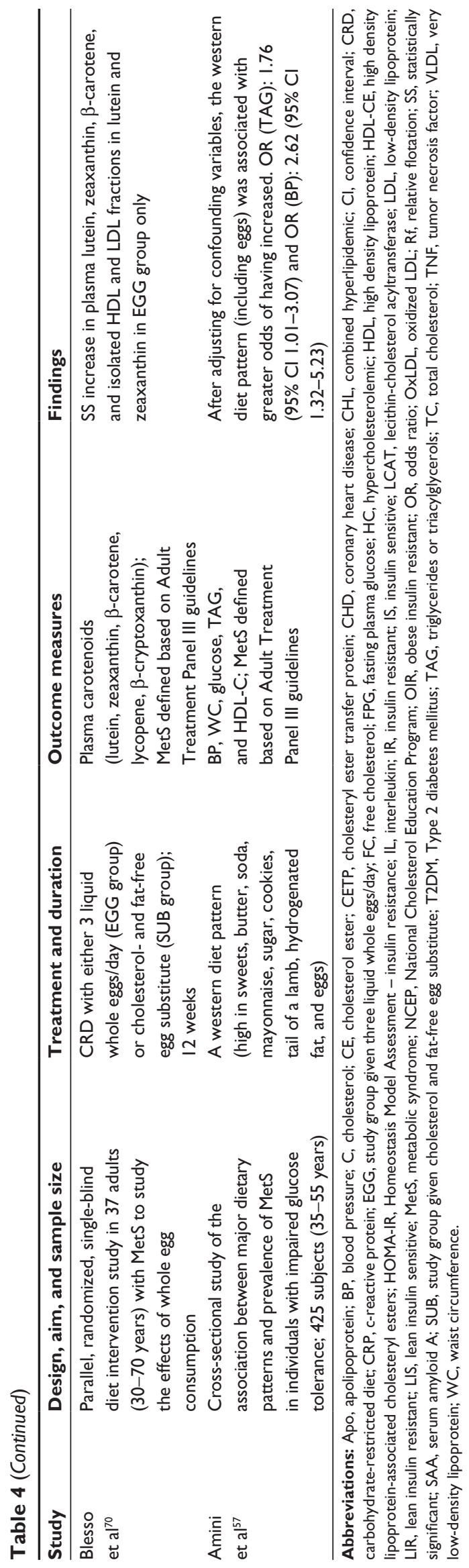

anthropometric measurements, including $\mathrm{WC}$, weight, and percent body fat in both groups $(P<0.01) .{ }^{69} \mathrm{In}$ an analysis of the effect of egg consumption on plasma carotenoids, there was a significant increase in plasma and lipoprotein (HDL and LDL), lutein, and zeaxanthin in the EGG group. ${ }^{70}$ While not the focus of this review, five studies were uncovered in the literature search that evaluated the relationship between egg consumption alone or as part of a dietary pattern and CHD/ T2DM risk factors (ie, MetS, lipoproteins, or other markers) in healthy subjects. ${ }^{56,59-62} \mathrm{It}$ is anticipated that if this search is expanded to include dietary cholesterol from all sources (not just eggs) or the benefits of low-glycemic index foods (of which eggs are one) on markers of cardiovascular health, this list of studies would be much more extensive.

All of the experimental studies conducted to examine the relationship between egg consumption and biomarkers of T2DM/CHD risk factors had small sample sizes, had vastly different study design and quality, and produced somewhat conflicting results, making it difficult to reach a coherent synthesis of the effect of egg consumption on various markers of T2DM/CHD risk factors among type II diabetics and individuals with risk factors for T2DM. Nevertheless, several of these studies showed that improvements in markers of risk for T2DM or MetS, including decreased serum glucose, $\mathrm{HbA1C}$, fasting serum insulin, body weight, WC, and trunk fat, ${ }^{49,55,56}$ can result from egg consumption when combined with targeted changes in the overall diets of T2DM patients, individuals who are overweight, and others with elevated CVD risk. In a randomized trial of men with T2DM, Pearce et al compared the effects of a 12-week calorie-restricted diet that included 2 eggs per day with the same diet including $100 \mathrm{~g}$ of lean animal protein substituted for the eggs. ${ }^{49}$ Both diets resulted in improvements in several markers of CVD risk, including weight loss, decreased TAG and total cholesterol levels, and improved apolipoprotein B levels, insulin sensitivity, and glycemic control. However, only the egg-fed group displayed significantly increased levels of HDL-C, a biomarker associated with decreased cardiovascular disease risk. In a similar study, Mutungi et al assessed the impact of feeding 3 eggs per day for 12 weeks in male subjects, some with MetS at baseline..$^{55}$ Egg or egg substitute was fed as part of a carbohydrate-restricted diet with no limitations on total energy intake. Both the egg-fed group and the cholesterolfree egg substitute group had similar statistically significant decreases in body weight, trunk fat, WC, and systolic BP; however, the egg-fed group had an approximately twofold greater decrease in diastolic BP than did the egg substitute group. In both groups, no statistically significant changes occurred in 
total cholesterol, cholesterol ratios, or in LDL-C levels, and plasma TAG was significantly decreased $(P<0.001)$. In agreement with the observations of Pearce et $a 1,{ }^{49}$ the subjects in the Mutungi et al trial who were fed egg displayed increased HDL-C, while those fed egg substitute did not. ${ }^{55}$ At baseline, 18 subjects in the Mutungi et al trial were classified as having MetS, and by the end of the 12-week study, only three subjects were classified as MetS, and all three of these subjects were in the egg substitute-fed group. ${ }^{55}$ In a similar study design, Ratliff et al observed decreased serum glucose and insulin and decreased IR in healthy subjects participating in both the egg and egg substitute groups of a carbohydrate-restricted dietary intervention. ${ }^{56}$ Participants reported greater satiety and had decreased caloric intake and body weight following the trial, despite the ad libitum nature of the diet, indicating the utility of these types of diets for at least short-term (12 week) weight loss for at-risk patients. The three articles that reported on a comparison of egg and egg substitute groups consuming a moderate carbohydrate-restricted diet for 12 weeks, in adults with MetS, showed that daily egg consumption resulted in favorable shifts in HDL lipid profiles beyond the observed increase in plasma HDL-C ${ }^{67}$, along with improved insulin resistance, ${ }^{68}$ increased plasma carotenoids,${ }^{70}$ decreased markers of inflammation, and improved anthropometric measurements. ${ }^{69}$ Together these studies suggest that egg consumption in combination with broader dietary changes could provide additional health benefits to at-risk individuals, beyond the benefits provided by the broad dietary change alone.

\section{Conclusion}

From the body of epidemiological studies, the finding of elevated CVD risk and egg consumption among diabetics was observed across studies, with the exception of the studies by Djoussé and Gaziano ${ }^{22}$ and Scrafford et al. ${ }^{16}$ The available prospective cohort studies that evaluated the relationship between egg consumption and CVD among diabetics had significant differences in study design and limitations and are not ideally suitable for a meta-analysis. In general, there is no consistency in the findings across epidemiological studies with respect to incident T2DM and egg consumption, and dietary confounders were not accounted for in all of the prospective studies. FFQs were used to assess exposure in all of the prospective studies with the exception of Ericson et al, ${ }^{65}$ who used a 7-day diary combined with an FFQ. However, there were discrepancies in the FFQ questions, for eg, some studies asked subjects how many times they ate eggs per week, rather than how many eggs they ate, and it is unclear whether eggs included as part of mixed dishes were included in the assessment. While there have been three meta-analyses based on these prospective studies, with reported findings of statistically significant increased CVD risks with egg consumption among diabetics and increased risk of T2DM associated with egg consumption among the general population, these findings are limited by the noted differences, and interpretation of these findings should be treated with caution.

A small number of experimental studies investigated the relationship between egg consumption and biomarkers for CHD risk among diabetics; however, study limitations and varying study designs limit our ability to interpret these results more broadly. Similarly, the somewhat conflicting results from the small number of experimental studies examining egg consumption and biomarkers of CHD risk among individuals with T2DM risk factors (measured by biomarkers) and the small number of subjects involved in these studies prevent broad interpretation and conclusions. Results from several small studies suggest that eggs that are part of a broader dietary intervention may reduce the risk of T2DM and MetS, thereby reducing the risk of CVD. However, given the noted study limitations, broad interpretation of these results should be avoided, and the findings of these studies should be investigated further.

\section{Author contributions}

NLT and LMB jointly directed the research, reviewed papers, drafted and revised the manuscript, and approved the manuscript as submitted; JMH conducted the main literature search, assisted with review, drafted and revised the manuscript, and approved the manuscript as submitted; CGS conducted supplemental literature searches, conducted study reviews, drafted and revised the manuscript, and approved the manuscript as submitted. All authors are accountable for all aspects of the work.

\section{Acknowledgments}

This work was partially funded by the Egg Nutrition Center (ENC). ENC did not contribute to the writing, analysis, or interpretation of research findings.

\section{Disclosure}

The authors report no conflicts of interest in this work.

\section{References}

1. National Cholesterol Education Program (NCEP) Expert Panel on Detection, Evaluation, and Treatment of High Blood Cholesterol in Adults (Adult Treatment Panel III). Third report of the National Cholesterol Education Program (NCEP) Expert Panel on Detection, Evaluation, and Treatment of High Blood Cholesterol in Adults (Adult Treatment Panel III) final report. Circulation. 2002;106(25):3143-3421. 
2. Shekelle RB, Shryock AM, Paul O, et al. Diet, serum cholesterol, and death from coronary heart disease. The Western Electric study. $N$ Engl J Med. 1981;304(2):65-70.

3. Stamler J, Shekelle R. Dietary cholesterol and human coronary heart disease: The epidemiologic evidence. Arch Path Lab Med. 1988; 112(10):1032-1040.

4. Hegsted DM, McGandy RB, Myers ML, Stare FJ. Quantitative effects of dietary fat on serum cholesterol in man. Am J Clin Nutr. 1965;17(5): 281-295.

5. Keys A, Parlin RW. Serum cholesterol response to changes in dietary lipids. Am J Clin Nutr. 1966;19(3):175-181.

6. ars.usda.gov [homepage on the Intranet]. USDA nutrient data laboratory: USDA national nutrient database for standard reference, release 23. US Department of Agriculture. Agricultural Research Service; 2013 [updated November 25, 2013; cited December 19, 2013]. Available from: http://www.ars.usda.gov/Services/docs.htm?docid=8964. Accessed December 28, 2013.

7. Krauss RM, Eckel RH, Howard B, et al. AHA Dietary Guidelines: revision 2000: A statement for healthcare professionals from the Nutrition Committee of the American Heart Association. Circulation. 2000;102(18):2284-2299.

8. Ascherio A, Rimm EB, Giovannucci EL, Spiegelman D, Stampfer M, Willett WC. Dietary fat and risk of coronary heart disease in men: cohort follow up study in the United States. BMJ. 1996;313(7049):84-90.

9. Hegsted DM, Ausman LM. Diet, alcohol and coronary heart disease in men. J Nutr. 1988;118(10):1184-1189.

10. Hu FB, Stampfer MJ, Manson JE, et al. Dietary fat intake and the risk of coronary heart disease in women. N Engl J Med. 1997;337(21): 1491-1499.

11. Kromhout D, Menotti A, Bloemberg B, et al. Dietary saturated and trans fatty acids and cholesterol and 25-year mortality from coronary heart disease: the Seven Countries Study. Prev Med. 1995;24(3):308-315.

12. Pietinen $P$, Ascherio A, Korhonen $P$, et al. Intake of fatty acids and risk of coronary heart disease in a cohort of Finnish men. The AlphaTocopherol, Beta-Carotene Cancer Prevention Study. Am J Epidemiol. 1997;145(10):876-887.

13. Kritchevsky SB, Kritchevsky D. Egg consumption and coronary heart disease: an epidemiologic overview. J Am Coll Nutr. 2000; 19(Suppl 5):S549-S555.

14. Qureshi AI, Suri FK, Ahmed S, Nasar A, Divani AA, Kirmani JF. Regular egg consumption does not increase the risk of stroke and cardiovascular diseases. Med Sci Monit. 2007;13(1):CR1-CR8.

15. Barraj L, Tran N, Mink P. A comparison of egg consumption with other modifiable coronary heart disease lifestyle risk factors: a relative risk apportionment study. Risk Anal. 2009;29(3):401-415.

16. Scrafford CG, Tran NL, Barraj LM, Mink PJ. Egg consumption and CHD and stroke mortality: a prospective study of US adults. Public Health Nutr. 2011;14(2):261-270.

17. He K, Merchant A, Rimm EB, et al. Dietary fat intake and risk of stroke in male US healthcare professionals: 14 year prospective cohort study. BMJ. 2003;327(7418):777-782.

18. Rong Y, Chen L, Zhu T, et al. Egg consumption and risk of coronary heart disease and stroke: dose-response meta-analysis of prospective cohort studies. BMJ. 2013;346:e8539.

19. Shin JY, Xun P, Nakamura Y, He K. Egg consumption in relation to risk of cardiovascular disease and diabetes: a systematic review and meta-analysis. Am J Clin Nutr. 2013;98(1):146-159.

20. Dietary Guidelines Advisory Committee. Report of the Dietary Guidelines Advisory Committee on the Dietary Guidelines for Americans, 2010: to the Secretary of Agriculture and the Secretary of Health and Human Services. Washington, DC: United States Department of Agriculture; United States Department of Health and Human Services; 2010.

21. Hu FB, Stampfer MJ, Rimm EB, et al. A prospective study of egg consumption and risk of cardiovascular disease in men and women. JAMA. 1999;281(15):1387-1394.
22. Djoussé L, Gaziano JM. Egg consumption in relation to cardiovascular disease and mortality: the Physicians' Health Study. Am J Clin Nutr. 2008;87(4):964-969.

23. American Diabetes Association. Diagnosis and classification of diabetes mellitus. Diabetes Care. 2011;34(Suppl 1):S62-S69.

24. World Health Organization. Definition and Diagnosis of Diabetes Mellitus and Intermediate Hyperglycemia. Report of a WHO/IDF Consultation. Geneva: World Health Organization; 2006.

25. Frayling TM. Genome-wide association studies provide new insights into type 2 diabetes aetiology. Nat Rev Genet. 2007;8(9):657-662.

26. Singh S, Dhingra S, Ramdath DD, Vasdev S, Gill V, Singal PK. Risk factors preceding type 2 diabetes and cardiomyopathy. J Cardiovasc Transl Res. 2010;3(5):580-596.

27. Bitzur R, Cohen H, Kamari Y, Shaish A, Harats D. Triglycerides and HDL cholesterol: stars or second leads in diabetes? Diabetes Care. 2009;32 Suppl 2:S373-S377.

28. Cheung BM. The hypertension-diabetes continuum. $J$ Cardiovasc Pharmacol. 2010;55(4):333-339.

29. Miller M. Managing mixed dyslipidemia in special populations. Prev Cardiol. 2010;13(2):78-83.

30. Duvnjak L, Duvnjak M. The metabolic syndrome - an ongoing story. J Physiol Pharmacol. 2009;60 Suppl 7:S19-S24.

31. Reaven GM. The metabolic syndrome: time to get off the merry-goround? J Intern Med. 2011;269(2):127-136.

32. Isomaa B, Almgren P, Tuomi T, et al. Cardiovascular morbidity and mortality associated with the metabolic syndrome. Diabetes Care. 2001;24(4):683-689.

33. Vijayaraghavan K. Treatment of dyslipidemia in patients with type 2 diabetes. Lipids Health Dis. 2010;9:144.

34. Schulze MB, Shai I, Manson JE, et al. Joint role of non-HDL cholesterol and glycated haemoglobin in predicting future coronary heart disease events among women with type 2 diabetes. Diabetologia. 2004;47(12):2129-2136.

35. King GL. The role of inflammatory cytokines in diabetes and its complications. J Periodontol. 2008;79(Suppl 8):S1527-S1534.

36. Yu Q, Gao F, Ma XL. Insulin says NO to cardiovascular disease. Cardiovasc Res. 2011;89(3):516-524.

37. Koyama H, Nishizawa Y. AGEs/RAGE in CKD: irreversible metabolic memory road toward CVD? Eur J Clin Invest. 2010;40(7):623-635.

38. Trichopoulou A, Psaltopoulou T, Orfanos P, Trichopoulos D. Diet and physical activity in relation to overall mortality amongst adult diabetics in a general population cohort. J Intern Med. 2006;259(6): 583-591.

39. Houston DK, Ding J, Lee JS, et al; Health ABC Study. Dietary fat and cholesterol and risk of cardiovascular disease in older adults: the Health ABC Study. Nutr Metab Cardiovasc Dis. 2011;21(6):430-437.

40. Djoussé L, Gaziano JM, Burning JE, Lee IM. Egg consumption and risk of type 2 diabetes in men and women. Diabetes Care. 2009;32(2): 295-300.

41. Djoussé L, Kamineni A, Nelson TL, et al. Egg consumption and risk of type 2 diabetes in older adults. Am J Clin Nutr. 2010;92(2):422-427.

42. Shi Z, Yuan B, Zhang C, Zhou M, Holmboe-Ottesen G. Egg consumption and the risk of diabetes in adults, Jiangsu, China. Nutrition. 2011;27(2):194-198.

43. Liese AD, Weis KE, Schulz M, Tooze JA. Food intake patterns associated with incident type 2 diabetes: the Insulin Resistance Atherosclerosis Study. Diabetes Care. 2009;32(2):263-268.

44. Qiu C, Frederick IO, Zhang C, Sorensen TK, Enquobahrie DA, Williams MA. Risk of gestational diabetes mellitus in relation to maternal egg and cholesterol intake. Am J Epidemiol. 2011;173(6):649-658.

45. Imamura F, Lichtenstein AH, Dallal GE, Meigs JB, Jacques PF. Generalizability of dietary patterns associated with incidence of type 2 diabetes mellitus. Am J Clin Nutr. 2009;90(4):1075-1083.

46. Tanasescu M, Cho E, Manson JE, Hu FB. Dietary fat and cholesterol and the risk of cardiovascular disease among women with type 2 diabetes. Am J Clin Nutr. 2004;79(6):999-1005. 
47. Arora RC, Agarwal N, Singh DK. A study of short term lipoprotein changes induced by single high cholesterol diet in healthy and diseases human volunteers. Mater Med Pol. 1991;23(4):299-301.

48. Romano G, Tilly-Kiesi MK, Patti L, et al. Effects of dietary cholesterol on plasma lipoproteins and their subclasses in IDDM patients. Diabetologia. 1998;41(2):193-200.

49. Pearce KL, Clifton PM, Noakes M. Egg consumption as part of an energy-restricted high-protein diet improves blood lipid and blood glucose profiles in individuals with type 2 diabetes. Br J Nutr. 2011;105(4): 584-592.

50. Jönsson T, Granfeldt Y, Ahrén B, et al. Beneficial effects of a Paleolithic diet on cardiovascular risk factors in type 2 diabetes: a randomized cross-over pilot study. Cardiovasc Diabetol. 2009;8:35.

51. Lindeberg S, Jönsson T, Granfeldt Y, et al. A Palaeolithic diet improves glucose tolerance more than a Mediterranean-like diet in individuals with ischaemic heart disease. Diabetologia. 2007;50(9):1795-1807.

52. Knopp RH, Retzlaff BM, Walden CE, et al. A double-blind, randomized, controlled trial of the effects of two eggs per day in moderately hypercholesterolemic and combined hyperlipidemic subjects taught the NCEP step I diet. J Am Coll Nutr. 1997;16(6):551-561.

53. Knopp RH, Retzlaff B, Fish B, et al. Effects of insulin resistance and obesity on lipoproteins and sensitivity to egg feeding. Arterioscler Thromb Vasc Biol. 2003;23(8):1437-1443.

54. Tannock LR, O'Brien KD, Knopp RH, et al. Cholesterol feeding increases $\mathrm{C}$-reactive protein and serum amyloid A levels in lean insulinsensitive subjects. Circulation. 2005;111(23):3058-3062.

55. Mutungi G, Ratliff J, Puglisi M, et al. Dietary cholesterol from eggs increases plasma HDL cholesterol in overweight men consuming a carbohydrate-restricted diet. J Nutr. 2008;138(2):272-276.

56. Ratliff J, Mutungi G, Puglisi MJ, Volek JS, Fernandez ML. Carbohydrate restriction (with or without additional dietary cholesterol provided by eggs) reduces insulin resistance and plasma leptin without modifying appetite hormones in adult men. Nutr Res. 2009;29(4):262-268.

57. Amini M, Esmaillzadeh A, Shafaeizadeh S, Behrooz J, Zare M. Relationship between major dietary patterns and metabolic syndrome among individuals with impaired glucose tolerance. Nutrition. 2010; 26(10):986-992.

58. Taggart C, Gibney J, Owens D, Collins P, Johnson A, Tomkin GH. The role of dietary cholesterol in the regulation of postprandial apolipoprotein B48 levels in diabetes. Diabet Med. 1997;14(12):1051-1058.

59. Pelletier $X$, Thouvenot $P$, Belbraouet $S$, et al. Effect of egg consumption in healthy volunteers: influence of yolk, white or whole-egg on gastric emptying and on glycemic and hormonal responses. Ann Nutr Metab. 1996;40(2):109-115.

60. Ratliff J, Leite JO, de Ogburn R, Puglisi MJ, VanHeest J, Fernandez ML. Consuming eggs for breakfast influences plasma glucose and ghrelin, while reducing energy intake during the next 24 hours in adult men. Nutr Res. 2010;30(2):96-103.
61. Delavar MA, Lye MS, Khor GL, Hassan ST, Hanachi P. Dietary patterns and the metabolic syndrome in middle aged women, Babol, Iran. Asia Pac J Clin Nutr. 2009;18(2):285-292.

62. Deshmukh-Taskar PR, O'Neil CE, Nicklas TA, et al. Dietary patterns associated with metabolic syndrome, sociodemographic and lifestyle factors in young adults: the Bogalusa Heart Study. Public Health Nutr. 2009;12(12):2493-2503.

63. Radzevičienė L, Ostrauskas R. Egg consumption and the risk of type 2 diabetes mellitus: a case-control study. Public Health Nutr. 2012;15(8):1437-1441.

64. Agrawal S, Ebrahim S. Prevalence and risk factors for self-reported diabetes among adult men and women in India: findings from a national cross-sectional survey. Public Health Nutr. 2012;15(6):1065-1077.

65. Ericson U, Sonestedt E, Gullberg B, et al. High intakes of protein and processed meat associate with increased incidence of type 2 diabetes. Br J Nutr. 2013;109(6):1143-1153.

66. Zazpe I, Beunza JJ, Bes-Rastrollo M, Basterra-Gortari FJ, Mari-Sanchis A, Martínez-González MÁ; SUN Project Investigators. Egg consumption and risk of type 2 diabetes in a Mediterranean cohort; the sun project Nutr Hosp. 2013;28(1):105-111.

67. Andersen CJ, Blesso CN, Lee J, et al. Egg consumption modulates HDL lipid composition and increases the cholesterol-accepting capacity of serum in metabolic syndrome. Lipids. 2013;48(6):557-567.

68. Blesso CN, Andersen CJ, Barona J, Volek JS, Fernandez ML. Whole egg consumption improves lipoprotein profiles and insulin sensitivity to a greater extent than yolk-free egg substitute in individuals with metabolic syndrome. Metabolism. 2013;62(3):400-410.

69. Blesso CN, Andersen CJ, Barona J, Volk B, Volek JS, Fernandez ML. Effects of carbohydrate restriction and dietary cholesterol provided by eggs on clinical risk factors in metabolic syndrome. J Clin Lipidol. 2013;7(5):463-471.

70. Blesso CN, Andersen CJ, Bolling BW, Fernandez ML. Egg intake improves carotenoid status by increasing plasma HDL cholesterol in adults with metabolic syndrome. Food Funct. 2013;4(2):213-221.

71. LiY, Zhou C, Zhou X, Li L. Egg consumption and risk of cardiovascular diseases and diabetes: a meta-analysis. Atherosclerosis. 2013;229(2): 524-530.

72. Fernandez ML. Dietary cholesterol provided by eggs and plasma lipoproteins in healthy populations. Curr Opin Clin Nutr Metab Care. 2006;9(1):8-12.

73. Fernandez ML, Calle M. Revisiting dietary cholesterol recommendations: does the evidence support a limit of $300 \mathrm{mg} / \mathrm{d}$ ? Curr Atheroscler Rep. 2010;12(6):377-383.

74. Grundy SM, Brewer HB Jr, Cleeman JI, Smith SC Jr, Lenfant C. Definition of metabolic syndrome: report of the National Heart, Lung, and Blood Institute/American Heart Association conference on scientific issues related to definition. Arterioscler Thromb Vasc Bio.1 2004; 24:e13-e18.

Diabetes, Metabolic Syndrome and Obesity: Targets and Therapy

Dovepress

\section{Publish your work in this journal}

Diabetes, Metabolic Syndrome and Obesity: Targets and Therapy is an international, peer-reviewed open-access journal committed to the rapid publication of the latest laboratory and clinical findings in the fields of diabetes, metabolic syndrome and obesity research Original research, review, case reports, hypothesis formation, expert opinion and commentaries are all considered for publication. The manuscript management system is completely online and includes a very quick and fair peer-review system, which is all easy to use. Visit http://www.dovepress.com/testimonials.php to read real quotes from published authors. 